Research Article

\title{
Overburden Migration and Failure Characteristics in Mining Shallow Buried Coal Seam with Thick Loose Layer
}

\author{
Zhuhe Xu $\left.{ }^{1}\right)^{1,2}$ Quansheng $\mathrm{Li}^{1,3}$ and Xiaobin $\mathrm{Li} \mathbb{D}^{1}$ \\ ${ }^{1}$ School of Energy and Mining Engineering, China University of Mining and Technology-Beijing, Beijing 100083, China \\ ${ }^{2}$ School of Coal Engineering, Shanxi Datong University, Datong 037003, China \\ ${ }^{3}$ State Key Laboratory of Water Resource Protection and Utilization in Coal Mining, Beijing 100011, China
}

Correspondence should be addressed to Zhuhe Xu; 845042618@qq.com

Received 28 May 2020; Revised 15 July 2020; Accepted 20 July 2020; Published 5 August 2020

Academic Editor: Antonio Caggiano

Copyright (C) 2020 Zhuhe Xu et al. This is an open access article distributed under the Creative Commons Attribution License, which permits unrestricted use, distribution, and reproduction in any medium, provided the original work is properly cited.

Quite a number of shallow buried coal seams (SBCS) are distributed in China. The overburden is easily damaged due to the mining of SBCS, resulting in water resources loss and surface damage. Taking 12403 working face of Wulanmulun coal mine in Shendong mining area as an example, this paper analyzed the overburden migration and failure characteristics after mining SBCS with thick loose layer based on actual measurement data and simulation results. The results show that the subsidence of strata in caving zone has no skewness feature along strike direction, while the subsidence of strata in fracture zone and bending subsidence zone shows skewness subsidence phenomenon. An interface exists in the overburden, and the movements of upper and lower strata at the interface have different characteristics. The cracks penetrating the whole strata exist in bedrock, not in aeolian sand. The height of water flowing fracture zone is $35.74 \mathrm{~m}-62.89 \mathrm{~m}$ according to the loss of fluid in the borehole and consistent with the results of numerical simulation and similar simulation. This study can provide a reference for the prediction of the height of water flowing fracture zone and the overburden migration in mining SBCS.

\section{Introduction}

Coal with different burial depths is the main energy source in China. However, coal mining has caused certain damage to the overburden $[1,2]$; that is, coal mining will cause the overburden movement and destruction, which result in a series of ecological damages, such as groundwater loss [3-5], rock fracture $[6,7]$, surface subsidence [8-10], and vegetation damage $[11,12]$. Mastering the characteristics of overburden damage is the premise and foundation of controlling or reducing the ecological damage. Therefore, many experts devote themselves to the research of this hot spot.

Zhou et al. [13-15] studied the movement and damage of overburden caused by coal mining through theoretical analysis and field measurement. On this basis, they put forward "horizontal three zones" and "vertical three belts." Huang and Xia [16] believed that the movement and deformation patterns of strata in the "vertical three belts" are different, and the strata in fracture zone have the most complex deformation. In view of the shortcoming that the traditional division method is difficult to describe the movement characteristics of the fracture zone mathematically, the "vertical four belts" of overburden is divided according to the movement characteristics of the strata in each layer. Both "vertical three belts" and "vertical four belts" are based on the zonation of rock strata failure and movement. There may be only "two belts" in overburden for shallow thick coal seam mining [17]. The fractures formed in overburden are the leakage channels of groundwater. Many scholars at home and abroad have adopted various methods to study the fractures in rock strata. Li et al. [18] used the physical similitude modeling method and field observations to study the breakage and migration law of overlying strata in the downward mining of extremely close coal seams. Zhang et al. [19] adopted field measurements and simulation using FDM and DEM coupled method to study longwall mining-induced damage and fractures. The study shows that 
the new method is able to give reasonable explanations for all in situ tests and handle the progressive caving of the rock layers. Li et al. [20] studied the developmental characteristics of cracks caused by mining coal seam with a shallow burial depth in a semidesert aeolian sand area and found that the dynamic crack above the working face has two developmental cycles (expansion to restoration).

In conclusion, many achievements have been made in the study of overburden migration and failure. The overburden forms "two belts," "three belts," or "four belts" after shallow coal seam mining, and the author believes that it is not only related to the buried depth of coal seam, but also affected by coal seam thickness; that is, the damage degree of the overburden is closely related to the depth-thickness ratio. He et al. [21] believed that when the depth-thickness ratio is relatively small $(<30)$, the surface movement and deformation will be discontinuous in space and time, and large cracks may appear on the surface. When the depth-thickness ratio is large $(>30)$, the surface movement and deformation will be continuous in space and time. In other words, although the buried depth is not large, the coal thickness is very small, and at this time, the overburden may also appear "three belts" after coal mining. In the light of the actual geological conditions and production conditions of Wulanmulun coal mine, the failure of overburden after compaction was studied in this paper. The average residual bulking coefficient of the overburden is 1.015 according to measured data [22]; that is, the expansion of all overburden above coal seam after compaction is only $1.5 \%$ compared with that before coal mining. Therefore, FLAC ${ }^{3 \mathrm{D}}$ numerical simulation and similar simulation were used to study the failure characteristics of overburden after compaction under the condition of super full mining in the shallow coal seam with thick loose layer, and the research results were verified by field measurement.

\section{Engineering Background}

The Wulanmulun coal mine is located in Ordos City, Inner Mongolia Autonomous Region, China (Figure 1). This study takes 12403 working face as the engineering background. The inclination length of 12403 working face is $300 \mathrm{~m}$, and the average buried depth, the dip angle, and the average thickness of $1^{-2}$ coal seam are $114.4 \mathrm{~m}, 1^{\circ}-3^{\circ}$, and $3.5 \mathrm{~m}$, respectively. The thickness of coal seam changes to some extent, but the change rule is obvious. The structure of coal seam is simple and reliable. There are many groups of weak planes and some fractures.

The comprehensive histogram is shown in Figure 2. The thickness of the bedrock layer and the loose layer are $62.5 \mathrm{~m}$ and $48.4 \mathrm{~m}$, respectively, which belongs to the condition of shallow buried and thick loose layer with a depth-thickness ratio of about 33 .

Core drilling machine was used to get the core samples of overburden and aeolian sand layer of $1^{-2}$ coal seam in Wulanmulun coal mine, and the corresponding basic rock mechanics experiments were carried out to obtain the basic mechanical parameters of coal, bedrock, and aeolian sand, as shown in Table 1.

\section{Hoek-Brown Strength Criterion and Determination of Rock Mass Parameters}

3.1. Hoek-Brown Strength Criterion Based on GSI. Hoek-Brown criterion was first proposed in 1980 [23]. The expression of GSI based on geological strength index is [24]

$$
\sigma_{1}=\sigma_{3}+\sigma_{c i}\left(m \frac{\sigma_{3}}{\sigma_{c i}}+s\right)^{a}
$$

where $\sigma_{1}$ is the maximum principal stress of rock mass under failure, $\mathrm{MPa} ; \sigma_{3}$ is the minimum principal stress, $\mathrm{MPa} ; \sigma_{c i}$ is the uniaxial compressive strength of rock, $\mathrm{MPa} ; m$ is the conversion value of Hoek-Brown constant $m_{i}$, and $m_{i}$ is the Hoek-Brown constant of intact rock; $s$ is the damage degree of rock mass, and its value range is $0-1 ; a$ is the constant depending on rock mass characteristics. $m, s$, and $a$ are Hoek-Brown constants of the rock mass. Their expressions are

$$
\begin{aligned}
& m=m_{i} \exp \left(\frac{\mathrm{GSI}-100}{28-14 D}\right), \\
& s=\exp \left(\frac{\mathrm{GSI}-100}{9-3 D}\right), \\
& a=\frac{1}{2}+\frac{1}{6}\left(e^{-(\mathrm{GSI} / 15)}-e^{-(20 / 3)}\right),
\end{aligned}
$$

where GSI is the geological strength index, which represents the fragmentation degree of rock mass and the mosaic structure of rock block; $D$ is the parameter indicating the disturbance degree of rock mass.

3.2. Determination of Parameters Based on Hoek-Brown Strength Criterion. (1) The determination of geological strength index (GSI): the GSI is determined by the geological environment, structural characteristics, and discontinuity properties of the rock mass. Because there is no specific quantitative index to describe the characteristics of rock mass and structural plane, it is more subjective in the division of rock mass structure. Su et al. [25] introduced the rock mass fragmentation index and weathering index to quantify the factors of rock mass structure and weathering condition. Therefore, it can be determined by the interpolation method according to the specific rock mass structure and weathering condition. (2) The disturbance parameter $D$ of rock blasting excavation can be determined according to Table 2 [26]. (3) Determination of $m_{i}$ : the material parameter $m_{i}$ of intact rock can be determined according to the rock type and property [27, 28]. (4) The uniaxial compressive strength $\sigma_{c i}$ of rock can be obtained by laboratory measurement.

\subsection{Determination of Mechanical Parameters of Rock Mass Based on Hoek-Brown Criterion}

(1) The determination of uniaxial tensile strength and compressive strength of rock mass. Based on formula 


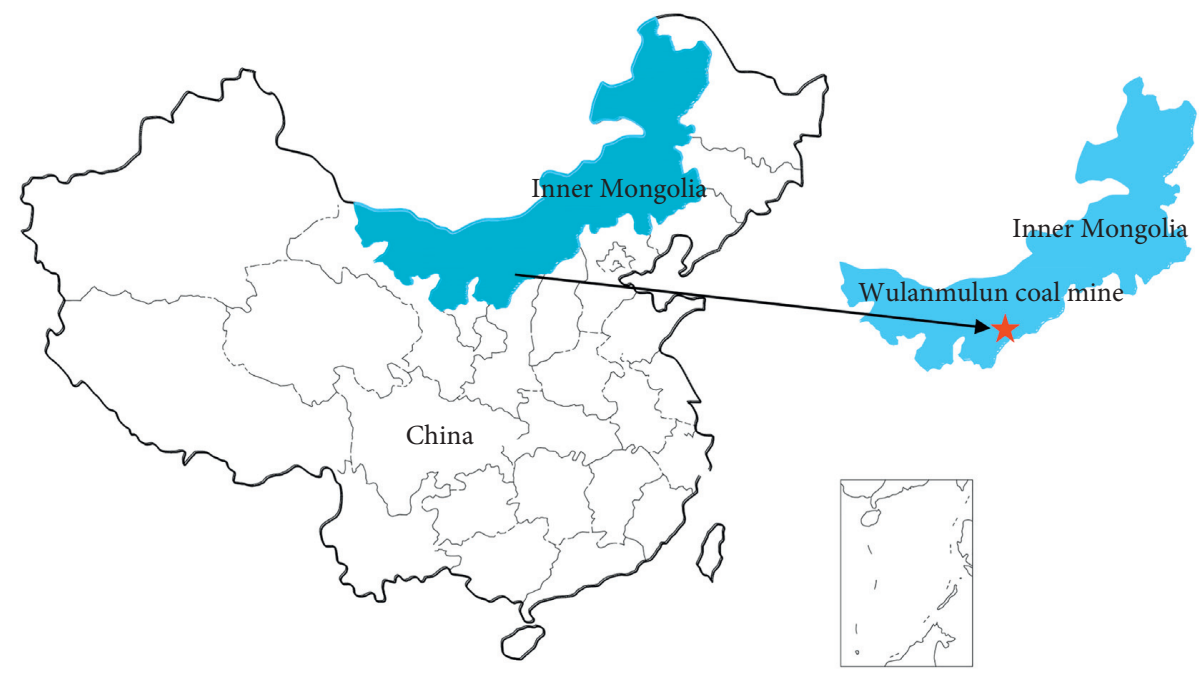

Figure 1: Traffic location map of Wulanmulun coal mine.

\begin{tabular}{|c|c|c|c|}
\hline Thickness $(\mathrm{m})$ & Depth $(\mathrm{m})$ & Lithology \\
\hline 48.4 & 48.4 & Aeolian sand & Fine sandstone \\
\hline 23.3 & 71.7 & Medium sandstone \\
\hline 18.2 & 89.9 & Coarse sandstone \\
\hline 1.90 & 91.8 & Sandy mudstone \\
\hline 2.10 & 93.9 & Fine sandstone \\
\hline 7.50 & 101.4 & Fine sandstone \\
\hline 5.30 & 106.7 & Medium sandstone \\
\hline 3.20 & 110.9 & Fine sandstone \\
\hline 3.50 & 114.4 & $1-2$ coal seam \\
\hline & 145.0 & \\
\hline & & \\
\hline & & \\
\hline
\end{tabular}

FIGURE 2: Comprehensive histogram.

TABLE 1: Experimental intensity values of coal and rock samples.

\begin{tabular}{lccccc}
\hline Lithology & $E(\mathrm{GPa})$ & $\mu$ & $\varphi\left({ }^{\circ}\right)$ & $c(\mathrm{MPa})$ & $\sigma_{c}(\mathrm{MPa})$ \\
\hline Aeolian sand & 12 & 0.30 & 10 & 0.01 & 11.6 \\
Coarse sandstone & 34 & 0.28 & 32 & 1.8 & 21.8 \\
Medium sandstone & 32 & 0.25 & 34 & 2.3 & 35.3 \\
Fine sandstone & 33 & 0.28 & 36 & 2.8 & 44.6 \\
Sandy mudstone & 20 & 0.30 & 32 & 2.0 & 26.8 \\
Coal seam & 15 & 0.35 & 36 & 1.2 & 10.5 \\
\hline
\end{tabular}

(1), the uniaxial tensile strength and compressive strength are derived by trial and error method.

$$
\begin{aligned}
& \sigma_{t}=\frac{1}{2} \sigma_{c i}\left(m-\sqrt{m^{2}+4 s}\right), \\
& \sigma_{c}=\sigma_{c i} \sqrt{s},
\end{aligned}
$$

where $\sigma_{t}$ and $\sigma_{c}$ are the tensile strength and compressive strength of rock mass, respectively.

(2) Determination of elastic modulus of rock mass: after introducing the disturbance coefficient $D$, the elastic modulus of rock mass can be expressed as follows:

When the uniaxial compressive strength of rock does not exceed $100 \mathrm{MPa}$,

$$
E=\left(1-\frac{D}{2}\right) \sqrt{\frac{\sigma_{c i}}{100}} 10^{(\mathrm{GSI}-10) / 40} \text {. }
$$

When the uniaxial compressive strength of rock exceeds $100 \mathrm{MPa}$,

$$
E=\left(1-\frac{D}{2}\right) 10^{(\mathrm{GSI}-10) / 40}
$$

(3) Determination of equivalent internal friction angle and cohesion of rock mass: according to HoekBrown criterion and Mohr-Coulomb criterion, it can be concluded that

$$
\begin{aligned}
& \varphi=\sin ^{-1}\left[\frac{3 a m\left(s+m \sigma_{3 n}\right)^{a-1}}{(1+a)(2+a)+3 a m\left(s+m \sigma_{3 n}\right)^{a-1}}\right] \\
& c=\frac{\sigma_{c i}\left[(1+2 a) s+(1-a) m \sigma_{3 n}\right]\left(s+m \sigma_{3 n}\right)^{a-1}}{\left.(1+a)(2+a) \sqrt{1+\left[6 a m\left(s+m \sigma_{3 n}\right)^{a-1}\right] /[(1+a)(2+a)}\right]},
\end{aligned}
$$


TABLE 2: Value of excavation disturbance parameter $D$.

\begin{tabular}{lc}
\hline Project disturbance & $D$ \\
\hline The rock mass is excellent, controlled blasting or rock excavation by machine & 0 \\
The rock mass quality is poor, manual prying or mechanical excavation & 0 \\
The tunnel is located in the squeezing stratum and has floor heave without invert & 0.5 \\
The blasting quality of hard rock tunnel is poor, and the influence depth of loosening is $2-3 \mathrm{~m}$ & 0.8 \\
The damage of surrounding rock is common and the blasting quality is poor in small-scale slope excavation & 1.0 \\
The damage of surrounding rock is general and the blasting quality is good in small-scale slope excavation & 0.7 \\
Large-scale production blasting, serious disturbance, production blasting & 0.7 \\
Large-scale production blasting, serious disturbance, mechanical excavation &
\end{tabular}

$$
\sigma_{3 n}=\frac{\sigma_{3 \max }}{\sigma_{c i}}
$$

where $\sigma_{3 \max }$ is the maximum value of the minimum principal stress under equivalent conditions, which is related to the rock mass type.

\section{Determination of Mechanical Parameters of Coal Seam and Rock Mass}

Combined with the actual geological conditions and production conditions of $1^{-2}$ coal seam in Wulanmulun coal mine, the corresponding mechanical parameters of coal seam and rock mass, which were used for numerical simulation calculation, were determined by the Hoek-Brown criterion.

Coal and rock blocks were taken from Wulanmulun coal mine, and their mechanical parameters were obtained in laboratory (Table 1). According to $[25,27,28]$ and Table 2 , the complete rock coefficient $m_{i}$, geological strength index (GSI), and excavation disturbance parameter $D$ can be obtained; $m, s$, and $a$ were obtained (Table 3 ) through formulas (2)-(4). The tensile strength and compressive strength of coal seam and rock strata were determined by formulas (5) and (6). The elastic moduli of coal seam and rock strata were determined by formula (7). The equivalent internal friction angle and cohesion of coal seam and rock strata were determined by formulas (9) and (10). The parameters of coal seam and rock strata are shown in Table 4.

\section{Numerical Simulation Study on Migration and Failure Features of Overburden}

5.1. Establishment of the Numerical Simulation Model. According to the actual production conditions and geological conditions of 12403 working face in Wulanmulun coal mine, a numerical calculation model was established through FLAC ${ }^{3 \mathrm{D}}$ simulation software, with the size of $600 \mathrm{~m}$ $(x) \times 500 \mathrm{~m}(y) \times 145 \mathrm{~m}(z)$, where $x$-axis represents the coal seam strike, $y$-axis represents the coal seam inclination, and $z$-axis represents the direction of vertical coal seam, as shown in Figure 3. The model adopted the Mohr-Coulomb criterion.

Because the coal seam is buried shallowly, the natural stress field is self-weight stress field. So, the upper part of
TABLE 3: Correlation parameter values of $\mathrm{H}-\mathrm{B}$ criterion.

\begin{tabular}{lcccccc}
\hline Lithology & GSI & $D$ & $m_{i}$ & $m$ & $s\left(10^{-4}\right)$ & $a$ \\
\hline Aeolian sand & 10 & 0.7 & 2 & 0.01 & 0.02 & 0.59 \\
Coarse sandstone & 33 & 0.7 & 19 & 0.48 & 0.61 & 0.52 \\
Medium sandstone & 35 & 0.7 & 15 & 0.41 & 0.83 & 0.52 \\
Fine sandstone & 40 & 0.7 & 12 & 0.44 & 1.70 & 0.51 \\
Sandy mudstone & 30 & 0.7 & 5 & 0.11 & 0.41 & 0.52 \\
Coal seam & 15 & 0.7 & 10 & 0.09 & 0.05 & 0.56 \\
\hline
\end{tabular}

TABle 4: Mechanic parameters of coal seam and rock strata.

\begin{tabular}{lccccc}
\hline Lithology & $E(\mathrm{GPa})$ & $\mu$ & $\varphi\left(^{\circ}\right)$ & $c(\mathrm{MPa})$ & $\sigma_{t}(\mathrm{MPa})$ \\
\hline Aeolian sand & 0.22 & 0.37 & 3 & 0.03 & 0.0023 \\
Coarse sandstone & 1.14 & 0.34 & 21 & 0.63 & 0.0033 \\
Medium sandstone & 1.63 & 0.31 & 19 & 0.96 & 0.0058 \\
Fine sandstone & 2.44 & 0.35 & 20 & 1.30 & 0.0170 \\
Sandy mudstone & 1.06 & 0.37 & 12 & 0.42 & 0.0100 \\
Coal seam & 0.28 & 0.42 & 10 & 0.12 & 0.0006 \\
\hline
\end{tabular}

model is free boundary, and other parts are fixed by displacement boundary conditions.

In order to obtain the characteristics of overburden migration and destruction accurately, 16 observation lines were arranged in the strike $(y=250 \mathrm{~m})$ and inclination $(x=300 \mathrm{~m})$, respectively. The observation lines were set at the surface and $0 \mathrm{~m}, 5 \mathrm{~m}, 10 \mathrm{~m}, 15 \mathrm{~m}, 20 \mathrm{~m}, 25 \mathrm{~m}, 30 \mathrm{~m}, 35 \mathrm{~m}$, $40 \mathrm{~m}, 50 \mathrm{~m}, 60 \mathrm{~m}, 70 \mathrm{~m}, 80 \mathrm{~m}, 90 \mathrm{~m}$, and $100 \mathrm{~m}$ away from the roof, respectively, as shown in Figure 4.

The inclination length of working face is $300 \mathrm{~m}$ and the advancing length is $400 \mathrm{~m}$ in the model. The coal pillars with the width of $100 \mathrm{~m}$ were left around the mining area to offset the boundary influence. The advancing process of the working face was simulated by step excavation method, and the single excavation distance was $10 \mathrm{~m}$ in order to simulate each advance of the working face.

\subsection{Migration and Stress Distribution Characteristics of Overburden on Strike Observation Surface}

5.2.1. Distribution Characteristics of Strata Subsidence on Strike Observation Surface. According to the simulation results, the subsidence distribution characteristics on different lines of observation surface $y=250 \mathrm{~m}$ can be obtained, as shown in Figure 5.

The distribution of strata subsidence from $20 \mathrm{~m}$ above the roof to the surface is asymmetric in the horizontal 


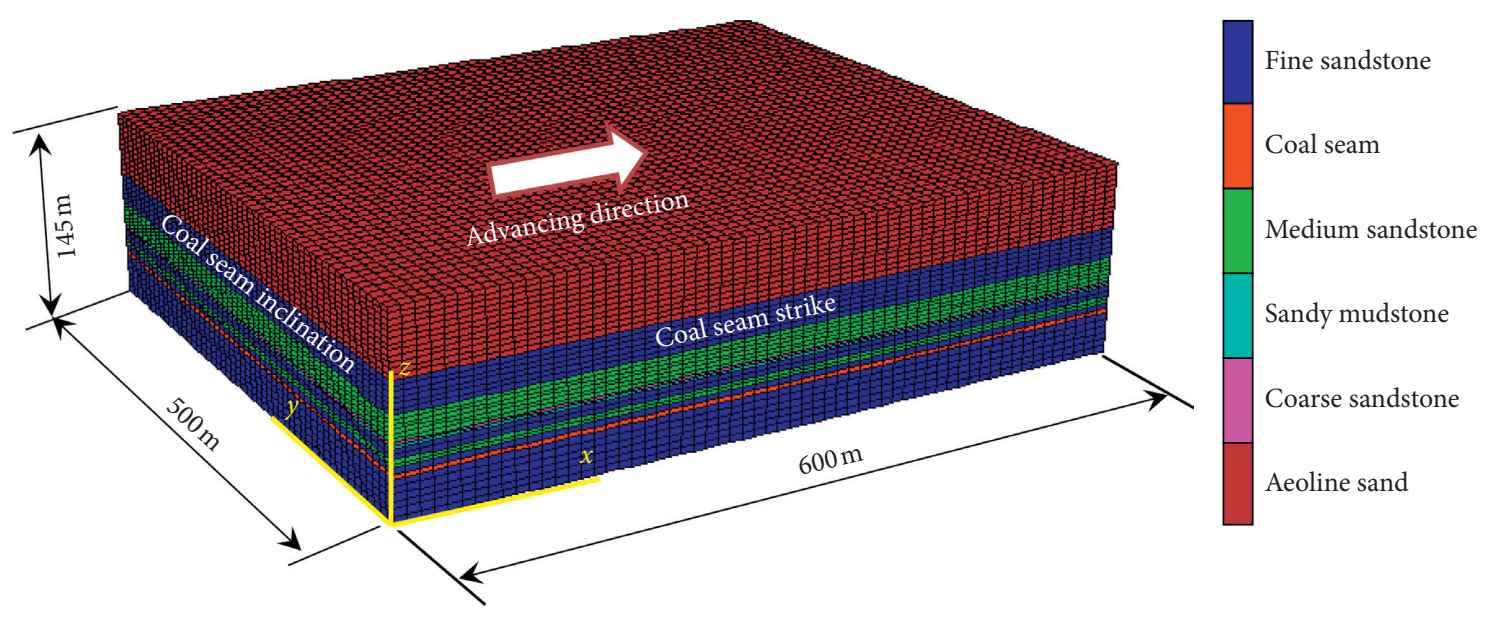

FIGURE 3: 3D numerical calculation model of mining.

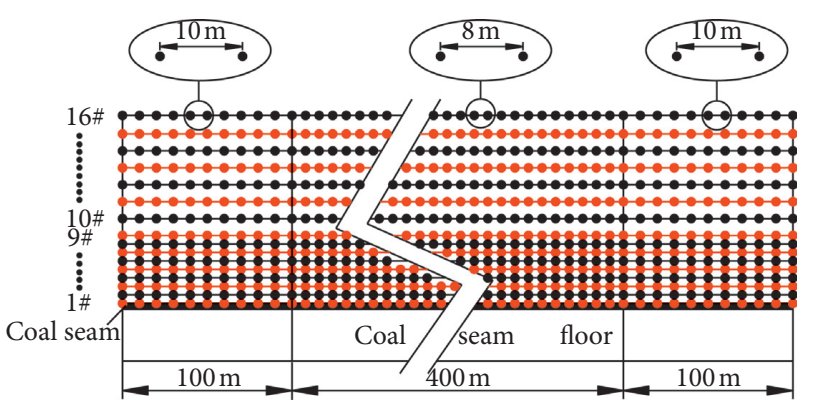

(a)

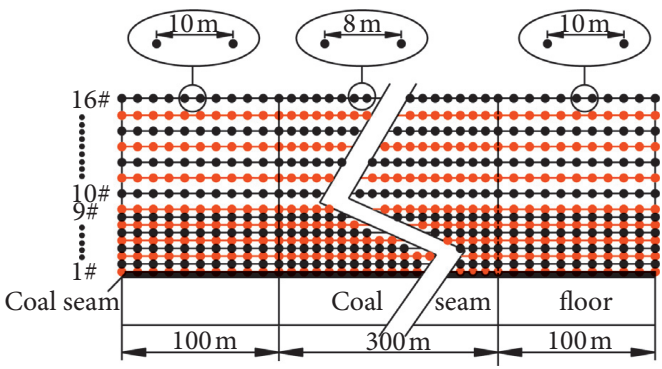

(b)

FIGURE 4: Layout of observation lines in observation surface. (a) Lines on observation surface $y=250 \mathrm{~m}$. (b) Lines on observation surface $x=300 \mathrm{~m}$.

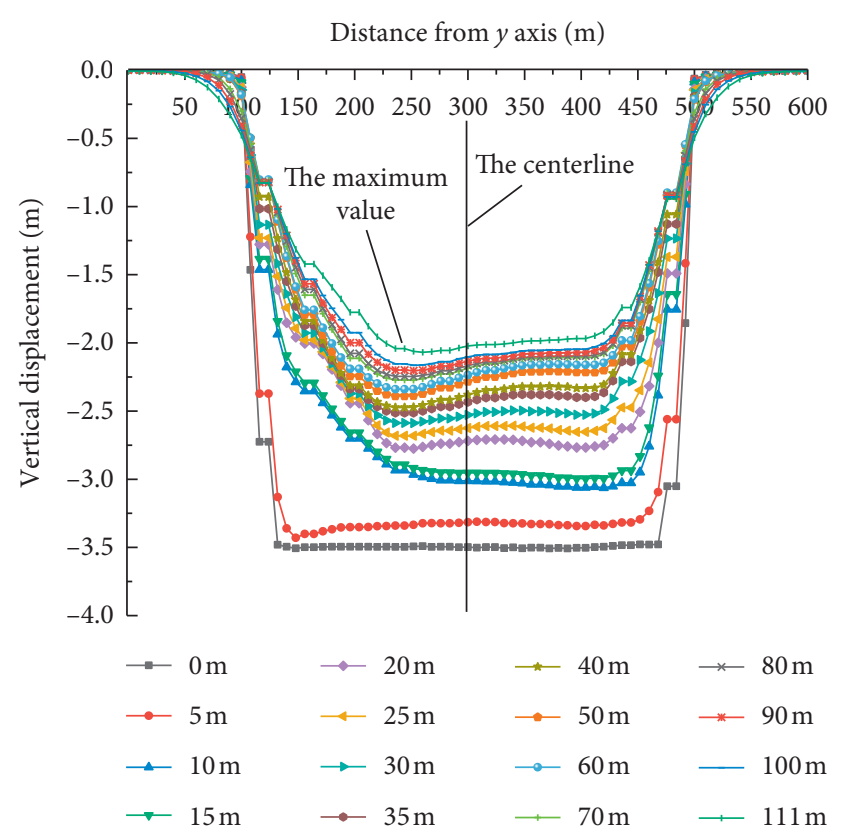

FIGURE 5: Distribution of vertical displacement on strike observation surface. direction, showing certain skewness characteristics [22], which makes the subsidence basin show asymmetry and a large amount of subsidence at the side of open-off cut. While the strata subsidence within about $20 \mathrm{~m}$ above the roof does not appear skewness characteristics, the distribution of strata subsidence at different distances from the roof in vertical direction is zonal. The settlement difference of adjacent survey lines within $0-20 \mathrm{~m}$ above the roof is not stable and with different sizes. The subsidence difference between adjacent survey lines within the range of $20 \mathrm{~m}-40 \mathrm{~m}$ above the roof is relatively stable, and the subsidence difference within $50 \mathrm{~m}$ above the roof to the surface is smaller than that within the range of $0-40 \mathrm{~m}$, with dense distribution, indicating that the rock stratum within this range is close to the overall subsidence. The maximum subsidence value of the surface is $2.1 \mathrm{~m}$, and the subsidence coefficient is 0.6 , which is close to the surface subsidence coefficient measured in Shendong mining area.

5.2.2. Distribution Characteristics of Horizontal Displacement of Strata on Strike Observation Surface. The horizontal displacement distribution characteristics on different lines of observation surface $y=250 \mathrm{~m}$ can be obtained through simulation, as shown in Figure 6. 


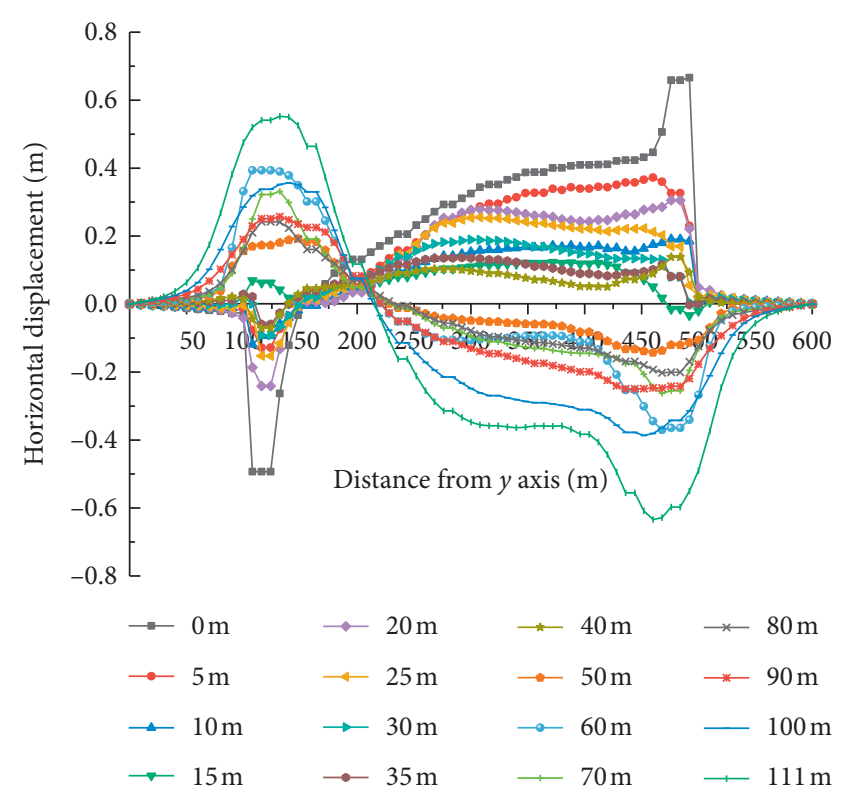

FIGURE 6: Distribution of horizontal displacement on strike observation surface.

An interface exists in the rock stratum, and the horizontal movement of the rock stratum from interface to surface is generally from both sides to the middle, while the horizontal movement of the rock stratum from coal seam roof to interface is generally from the middle to both sides, which indicate the horizontal movement of rock stratum within the range of $50 \mathrm{~m}$ above the roof to the surface is from both sides to the middle, while the horizontal movement of the rock stratum within the range of $40 \mathrm{~m}$ above the roof is generally from the middle to both sides. The interface of horizontal movement in rock stratum is located between $40 \mathrm{~m}$ and $50 \mathrm{~m}$ above the roof. The horizontal movement of rock stratum above the interface is generally greater than that of lower rock stratum. The zero point of horizontal movement of rock stratum is not in the middle of mining area, but inclined to the open-off cut side. The horizontal movement zero point of rock strata above and below the interface does not coincide, and the horizontal movement zero point of the lower stratum below interface is closer to the open-off cut. The horizontal movement directions of stratum between the horizontal movement zero points of upper and lower strata of the interface are the same, but the horizontal movements are different except the intersection point.

Along the strike observation surface, it can be divided into two parts: one is the opposite direction of horizontal movement of the upper and lower strata of interface on both sides; the other is the same direction of horizontal movement between two zero points. The horizontal displacement direction of adjacent strata is different, or same with different movement amount, and in both cases, there will be interlaminar dislocation, including the opposite direction dislocation and the same direction dislocation (Figure 7). The interlaminar dislocation was observed (Figure 8) by other scholars in the field and similar simulation study.
5.2.3. Vertical Stress Distribution Characteristics of Strata on Strike Observation Surface. The vertical stress distribution characteristics on different lines of observation surface $y=250 \mathrm{~m}$ can be obtained through simulation, as shown in Figure 9.

Along the advancing direction of working face, the vertical stress value in the rock stratum within a range of $50 \mathrm{~m}$ below surface keeps basically unchanged, indicating that the coal mining has no significant influence on the vertical stress of rock stratum within this range. The rock stratum within $60 \mathrm{~m}$ above the roof along the advancing direction of working face can be divided into original rock stress area, stress concentration area, stress reduction area, stress concentration area, recompaction area, stress reduction area, stress concentration area, and original rock stress area. The rock strata above the open-off cut and the working face have arch structure, except stress concentration at the arch foot and stress reduction below the arch, and the rest are basically in original rock stress state.

\subsection{Movement and Stress Distribution of Overburden on Inclination Observation Surface}

5.3.1. The Distribution Characteristics of the Subsidence on Inclination Observation Surface. The distribution characteristics of subsidence on different lines of observation surface $x=300 \mathrm{~m}$ can be obtained through simulation, as shown in Figure 10.

The subsidence of each stratum from the roof to the surface distributes symmetrically due to nearly flat coal seam. The subsidence of the strata in different layers is also zonal in vertical direction, which is the same as that of the strata on strike observation surface. Namely, the subsidence difference of strata in different layers within the range of $20 \mathrm{~m}$ above the roof varies in size. However, the subsidence difference in the strata of $20 \mathrm{~m}$ above the roof to the surface is relatively stable, and that within $50 \mathrm{~m}$ above the roof to the surface is relatively small, which indicate that the survey lines are densely distributed.

\subsubsection{Horizontal Displacement Features of Overburden on} the Inclination Observation Surface. The horizontal displacement distribution characteristics on different lines of observation surface $x=300 \mathrm{~m}$ can be obtained through simulation, as shown in Figure 11.

An interface exists within the range of $40 \mathrm{~m}-50 \mathrm{~m}$ on the inclination observation surface. The horizontal movement direction of overburden above the interface is from both sides to the middle, while the overburden below the interface is from the middle to both sides. The zero point of horizontal movement of the layer is in the middle of mining area, and the zero points of the upper and lower layers of interface coincide with each other. There are only two different moving direction areas of horizontal movement of the upper and lower strata of interface along the inclination observation surface, and there is no same moving direction area of horizontal movement. The horizontal movement of the 


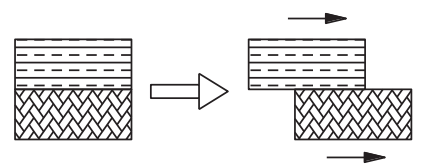

(a)

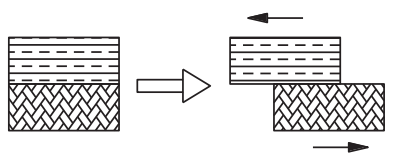

(b)

Figure 7: Types of strata dislocation. (a) Same direction dislocation. (b) Isokinetic dislocation.

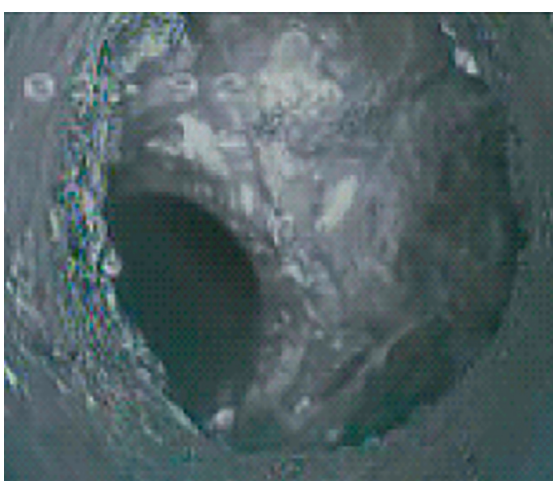

(a)

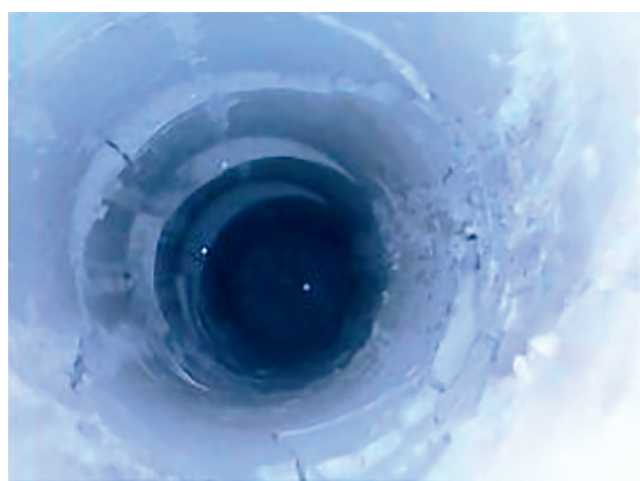

(b)

FIgURE 8: Layer dislocation phenomenon. (a) Field measurement [29]. (b) Similar simulation [30].

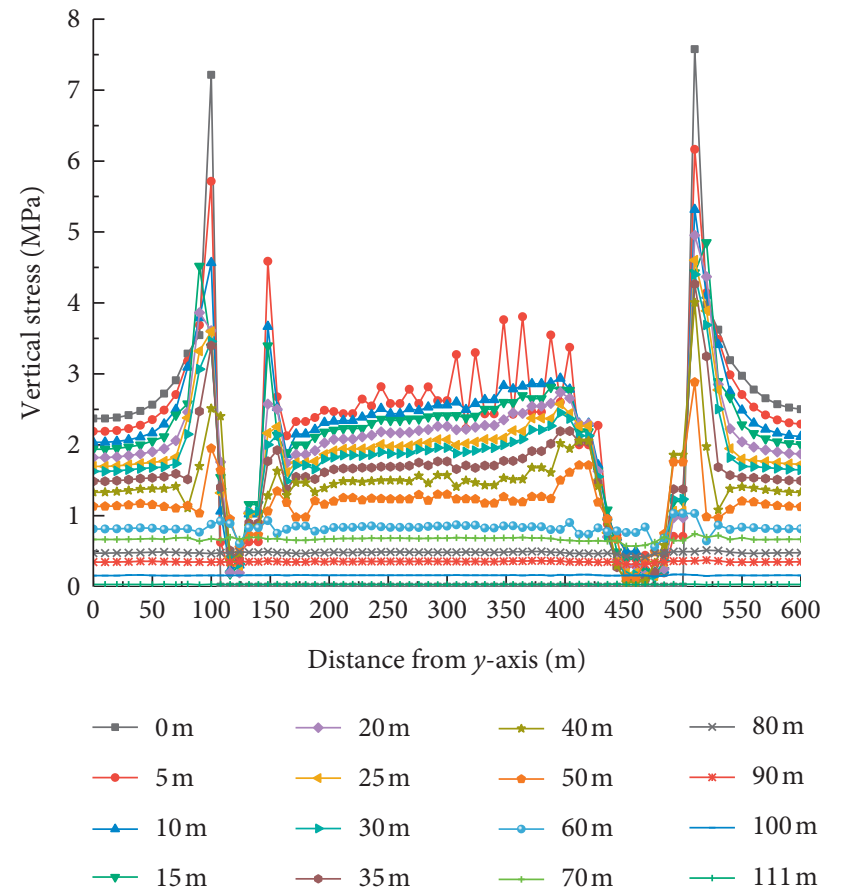

FIgURE 9: Distribution of vertical stress on strike observation surface.

upper strata of interface is larger than that of the lower strata on the whole.

5.3.3. The Vertical Stress Distribution Features of Overburden on the Inclination Observation Surface. The vertical stress distribution characteristics on different lines of observation

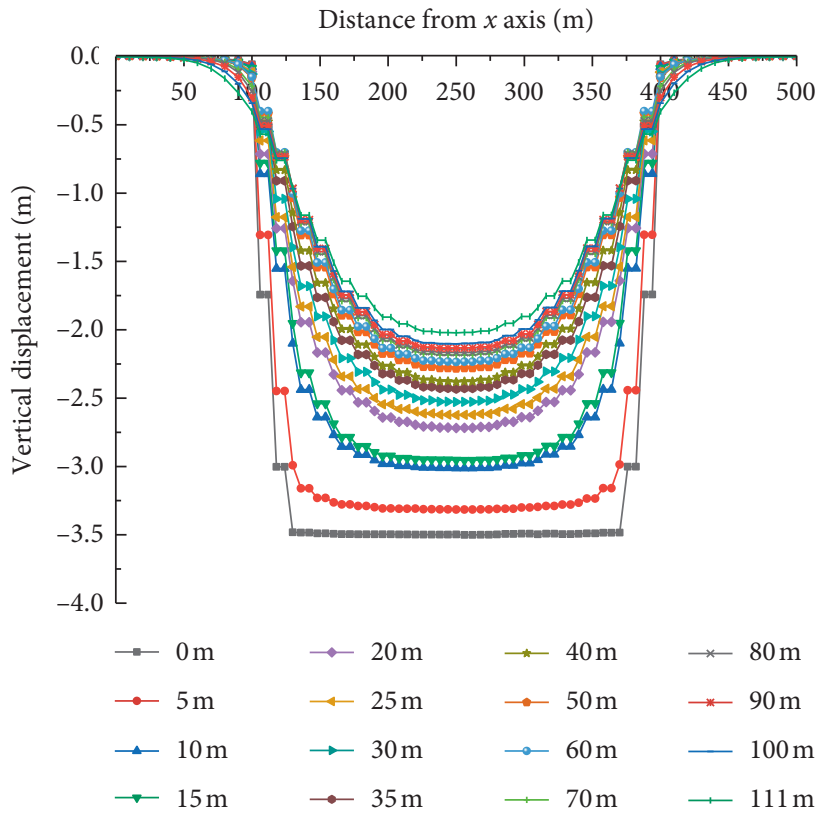

FIgURE 10: Distribution of vertical displacement on inclination observation surface.

surface $x=300 \mathrm{~m}$ can be obtained through simulation, as shown in Figure 12.

The vertical stress in the strata within $50 \mathrm{~m}$ below the surface basically remains unchanged along the inclination direction and distributes in a " $W$ " shape as a whole along the inclination direction. The strata within $60 \mathrm{~m}$ above the roof can be divided into original rock stress area, stress concentration area, stress reduction area, stress concentration 


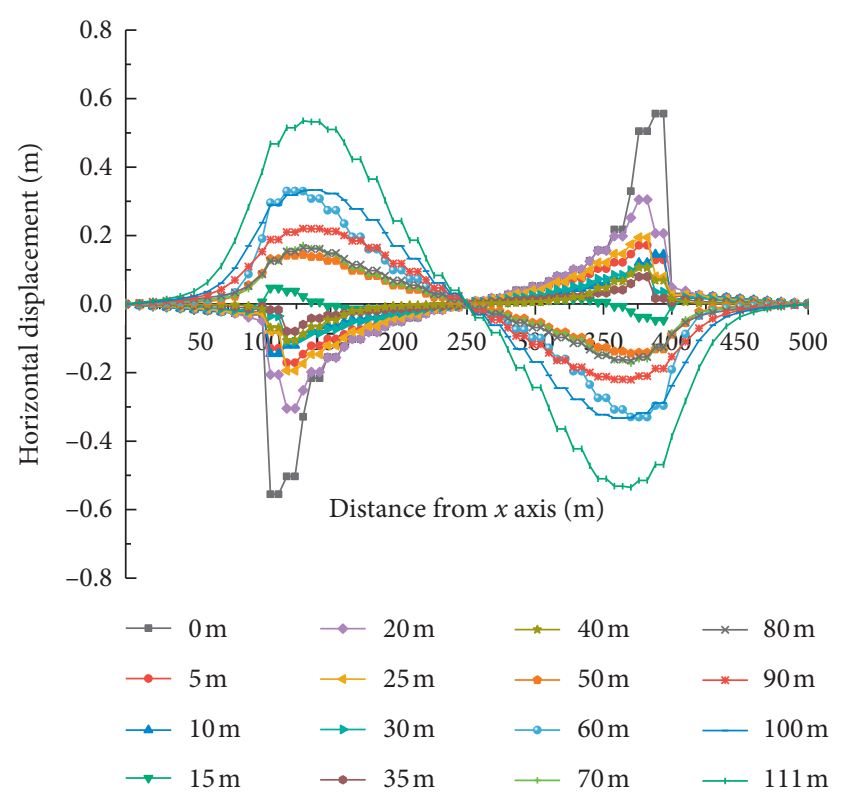

Figure 11: Distribution of horizontal displacement on inclination observation surface.

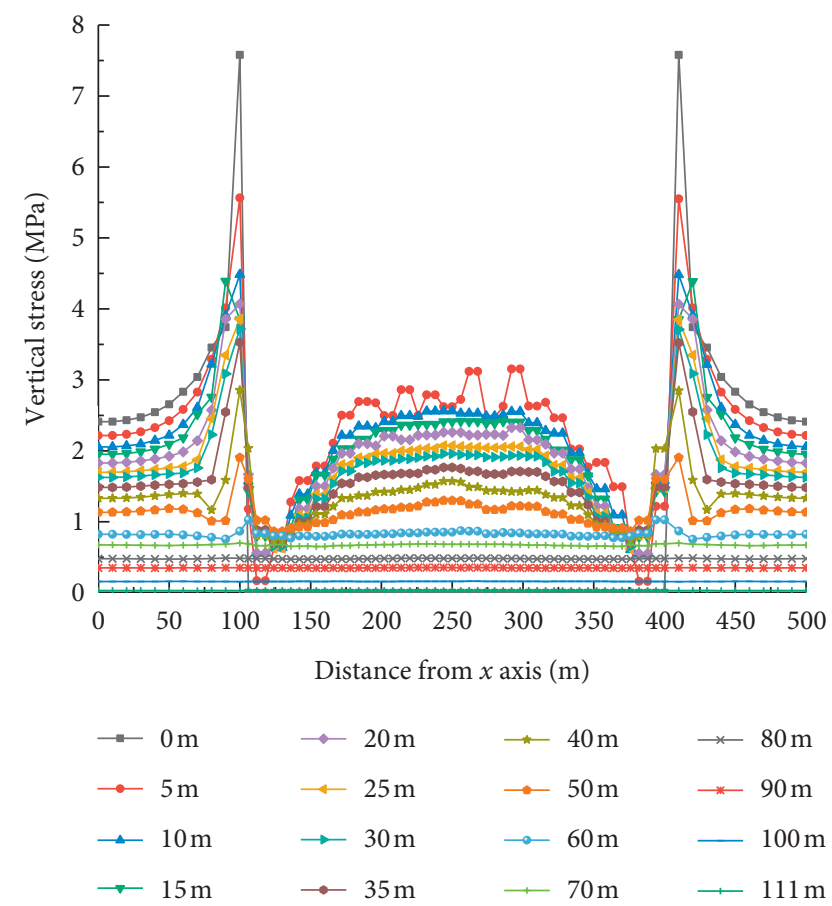

FIGURE 12: Distribution of vertical stress on inclination observation surface.

area, and original rock stress area along the inclination direction.

5.4. Failure Characteristics of Overburden. The distribution characteristics of the plastic zone of overburden obtained from the simulation are shown in Figure 13.

All the strata from the roof to the surface have suffered different degrees and different types of damage due to shallow depth. The bedrock layer is mainly located within $62.5 \mathrm{~m}$ above the roof and in the state of tensile and shear failure. The aeolian sand layer is located within about $50 \mathrm{~m}$ below the surface, mainly in the state of shear failure, which shows the dislocation caused by the different movement of the upper and lower parts of aeolian sand layer in the process of movement and deformation. The simulation results show that the surface aeolian sand has tension failure, and cracks may appear on the surface in site.

\section{Similar Simulation of Movement and Failure Characteristics of Overburden}

6.1. Similar Simulation Model. A two-dimensional plane similar model test-bed with the size of $1.8 \mathrm{~m} \times 1.2 \mathrm{~m} \times 0.4 \mathrm{~m}$ was used in the experiment. The height of model with 10 layers from coal seam floor to the surface is $121.9 \mathrm{~m}$. The thickness of coal seam, bedrock layer, and overburden are $3.5 \mathrm{~m}, 62.5 \mathrm{~m}$, and $48.4 \mathrm{~m}$, respectively. The aeolian sand layer is simulated with gravel and sand, as shown in Figure 14.

The research of similar simulation meets the similarity of geometry, motion, and boundary conditions as well as the proportion of corresponding physical quantities. The linear ratio, the unit weight ratio, the stress ratio, and the time ratio of this model are $1: 100,1: 1.5,1: 150$, and $1: 10$, respectively. The materials are as follows: aggregate: ordinary river sand with particle size less than $1.5 \mathrm{~mm}$; cement: gypsum and lime; and layered material: mica powder. The main mechanical and geometric parameters of the model are shown in Table 5.

6.2. Subsidence Characteristics of Overburden. In order to monitor the subsidence of the bedrock layer, there were 7 monitoring lines in the bedrock above coal seam and 17 columns along the strike. The horizontal spacing between displacement monitoring point is $100 \mathrm{~mm}$. The vertical spacing between the first and sixth lines is $80 \mathrm{~mm}$, and the vertical distance between the sixth and seventh lines is $100 \mathrm{~mm}$. The first monitoring line is $55 \mathrm{~mm}$ away from the coal seam, and the first column on the left is $200 \mathrm{~mm}$ away from the boundary. The monitoring results are shown in Figure 15.

The subsidence of rock stratum appears zonal. The maximum subsidence of the rock stratum within $21.5 \mathrm{~m}-55.5 \mathrm{~m}$ above the roof is inclined to the open-off cut. There is no subsidence skewness of the rock stratum within $0 \mathrm{~m}-21.5 \mathrm{~m}$ above the roof.

6.3. Failure Characteristics of Overburden. The failure of rock stratum is zonal, forming the caving zone, fracture zone and bending subsidence zone. According to the analysis of rock failure, the height of water conducting fracture zone is $62.8 \mathrm{~m}$. No fracture through the whole layer exists in aeolian sand layer because of the fluidity, which makes the fracture have a certain self-repairing ability. The transfixion fractures in rock layer, the main water channel, mainly distribute on both sides of the mining area, and those in the middle of 


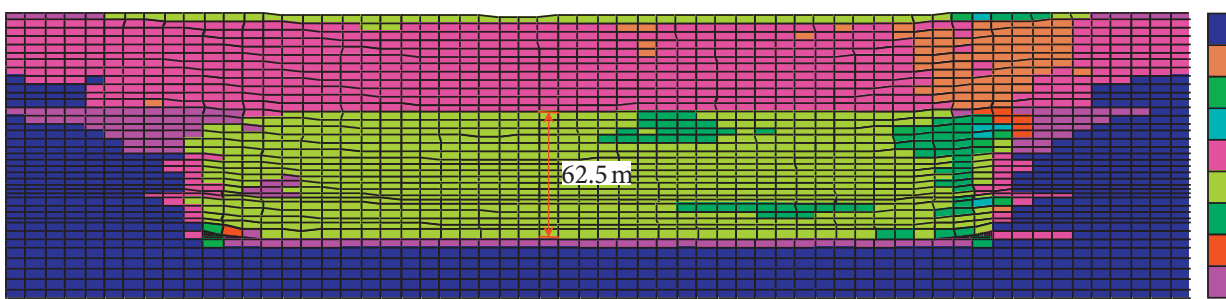

(a)

(b)

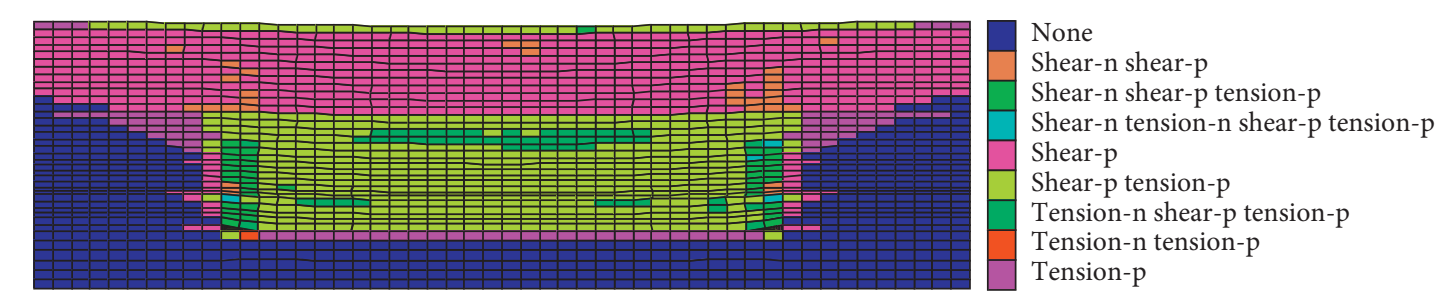

None

Shear-n shear-p

Shear-n shear-p tension-p

Shear- $n$ tension- $n$ shear- $p$ tension- $p$ Shear-p

Shear-p tension-p

Tension-n shear- $p$ tension- $p$

Tension- $n$ tension- $\mathrm{p}$

Tension-p

Figure 13: Overburden damage caused by coal seam mining. (a) $y=250 \mathrm{~m}$. (b) $x=300 \mathrm{~m}$.

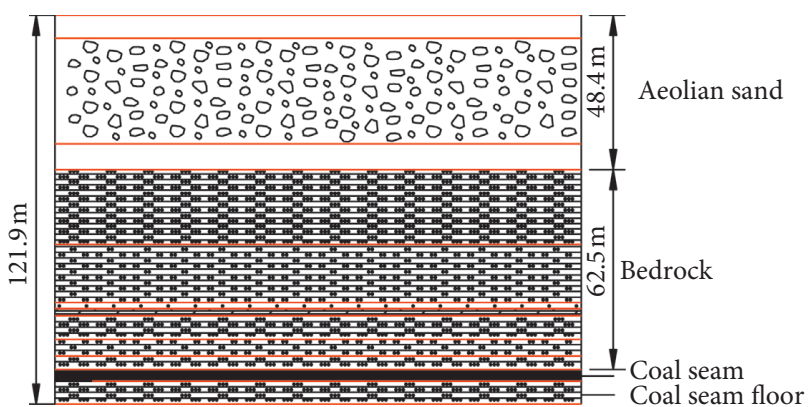

Figure 14: Similar simulation model.

TABLE 5: The main mechanical and geometric parameters of the model.

\begin{tabular}{lccc}
\hline Lithology & $\rho\left(\mathrm{g} / \mathrm{cm}^{3}\right)$ & $\sigma_{c}(\mathrm{MPa})$ & Strata thickness $(\mathrm{cm})$ \\
\hline Aeolian sand & 1.05 & 0.08 & 48.4 \\
Fine sandstone & 1.87 & 0.30 & 23.3 \\
Medium sandstone & 1.75 & 0.24 & 18.2 \\
Coarse sandstone & 1.62 & 0.15 & 1.9 \\
Sandy mudstone & 1.69 & 0.18 & 2.1 \\
Fine sandstone & 1.87 & 0.30 & 7.5 \\
Medium sandstone & 1.75 & 0.24 & 5.3 \\
Fine sandstone & 1.87 & 0.30 & 4.2 \\
Coal seam & 0.94 & 0.07 & 3.5 \\
Fine sandstone & 1.87 & 0.30 & 7.5 \\
\hline
\end{tabular}

mining area mostly distribute in the lower part of caving zone and fracture zone. The fractures can be divided into horizontal fractures, vertical fractures, and oblique fractures according to the occurrence, as shown in Figure 16.

\section{Actual Measurement of Overburden Failure Caused by Coal Mining}

The results of physical simulation and numerical simulation are shown in Figure 17. It can be seen from the figure that the

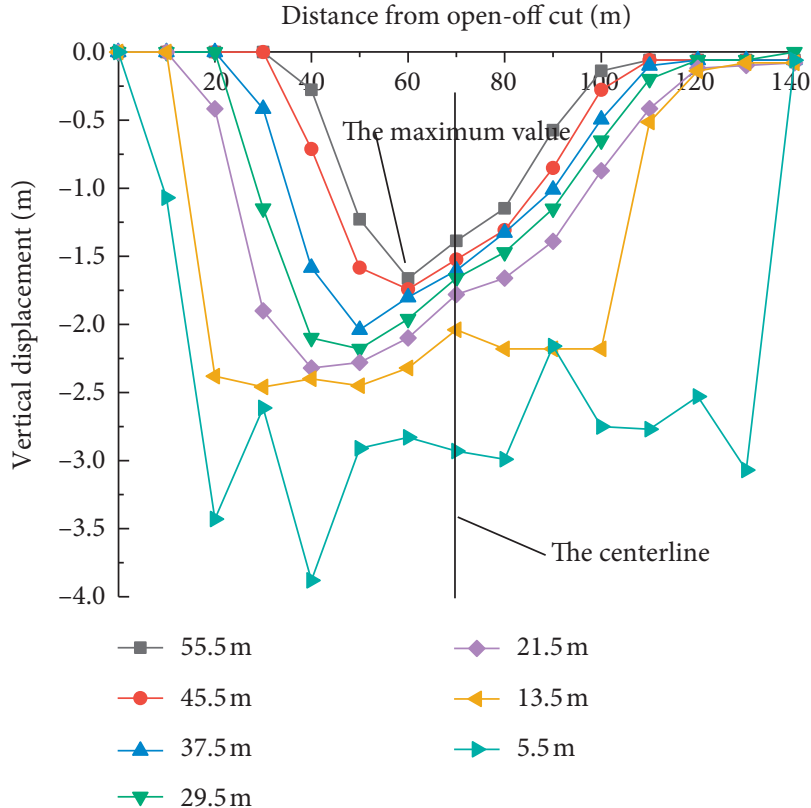

Figure 15: Vertical displacement distribution of bedrock strata.

results obtained by the two methods are very close, and the accuracy of research results needs to be verified by field measurement.

In order to measure the damage of overburden after coal mining in Wulanmulun mine, two observation boreholes WM1 and WM2 were arranged along the coal seam strike in 12403 working face. The observation results were analyzed by considering the situation of drilling process in field and the change curve of drilling flushing fluid loss comprehensively, as shown in Figure 18.

The height of water conducting fracture zone at hole WM1 is $62.89 \mathrm{~m}$, and the height at hole WM2 is $35.74 \mathrm{~m}$. The heights of water conducting fracture zone determined by numerical simulation and similar simulation are $62.5 \mathrm{~m}$ and $62.8 \mathrm{~m}$, 


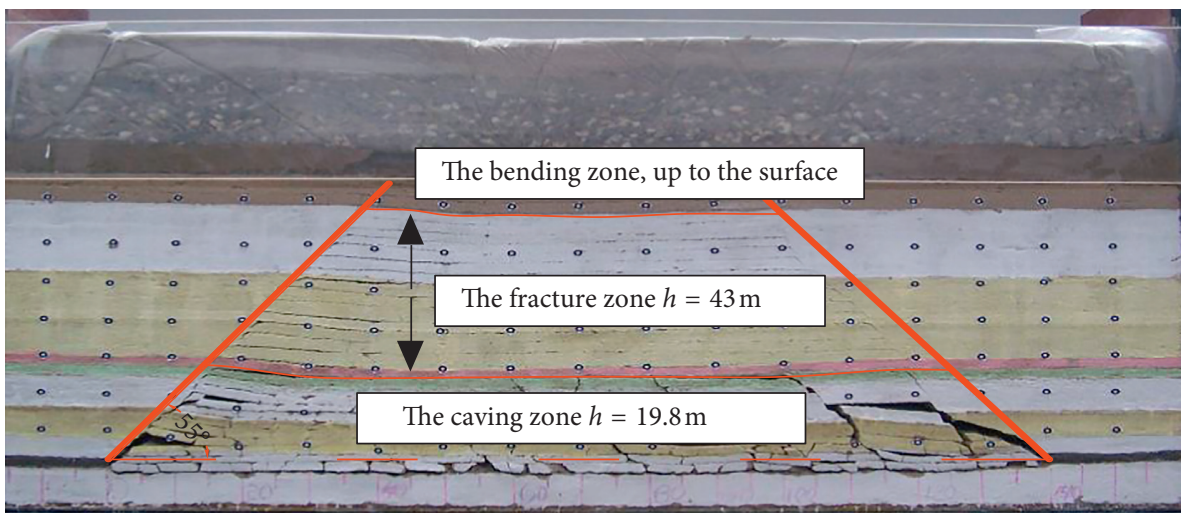

(a)

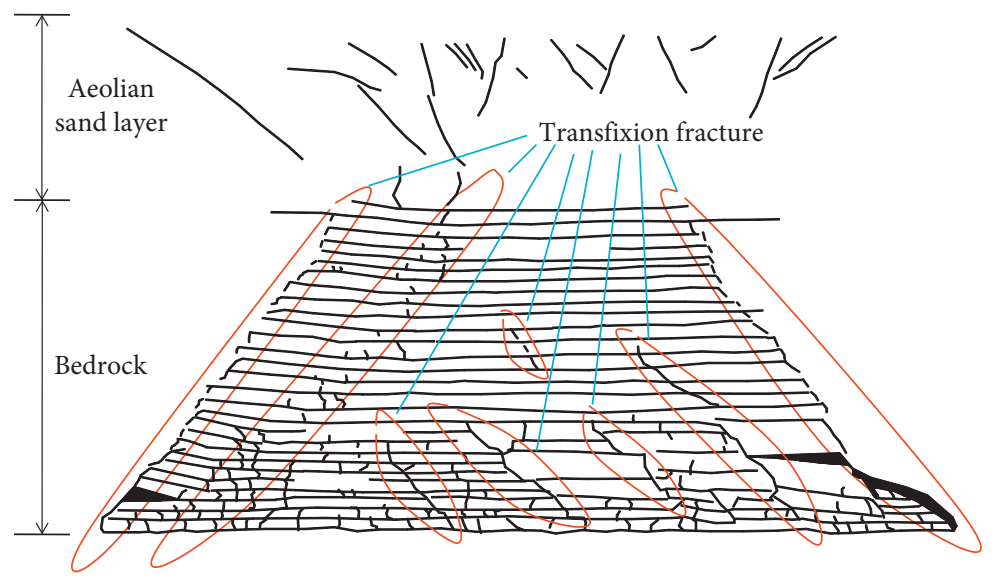

(b)

FIGURE 16: Overlying rock damage caused by coal seam mining. (a) Failure of overburden. (b) Distribution of rock fracture.

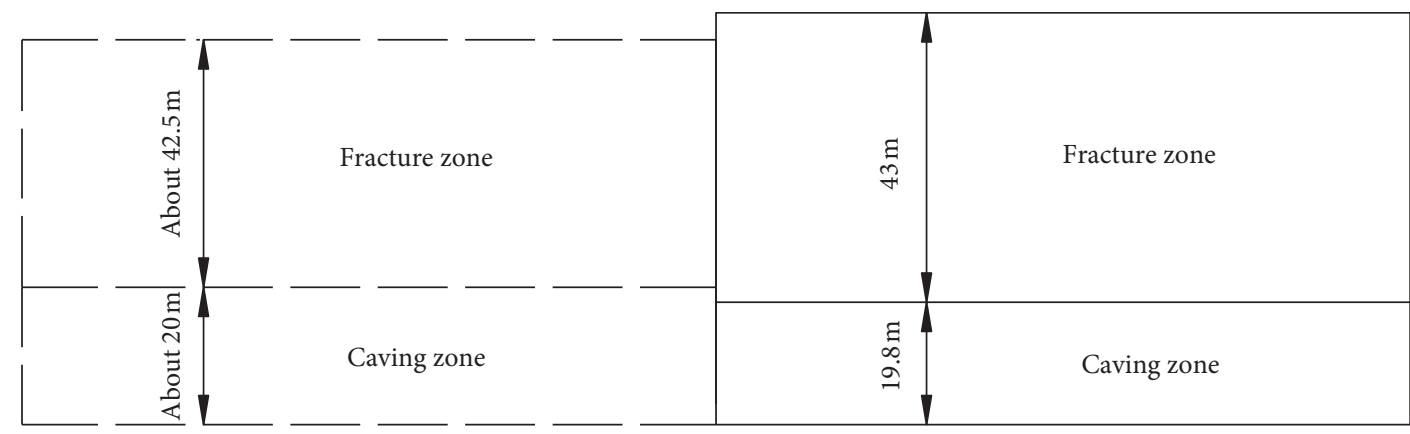

Numerical simulation results

Physical simulation results

Figure 17: Comparison of physical simulation results and numerical simulation results.

respectively, which are within the range of $35.74 \mathrm{~m}-62.89 \mathrm{~m}$ measured in field, and are consistent with the height of hole WM1.

The results of numerical simulation, similar simulation, and field measurement show that although the coal seam depth of 12403 working face is small, the overburden forms "three belts," which is different from the research result of "two belts" formed in overburden due to some shallow coal seam mining, but it is consistent with the literature [21]. The reason may be that although the coal seam depth in 12403 working face is small, its depth-thickness ratio is relatively large. 


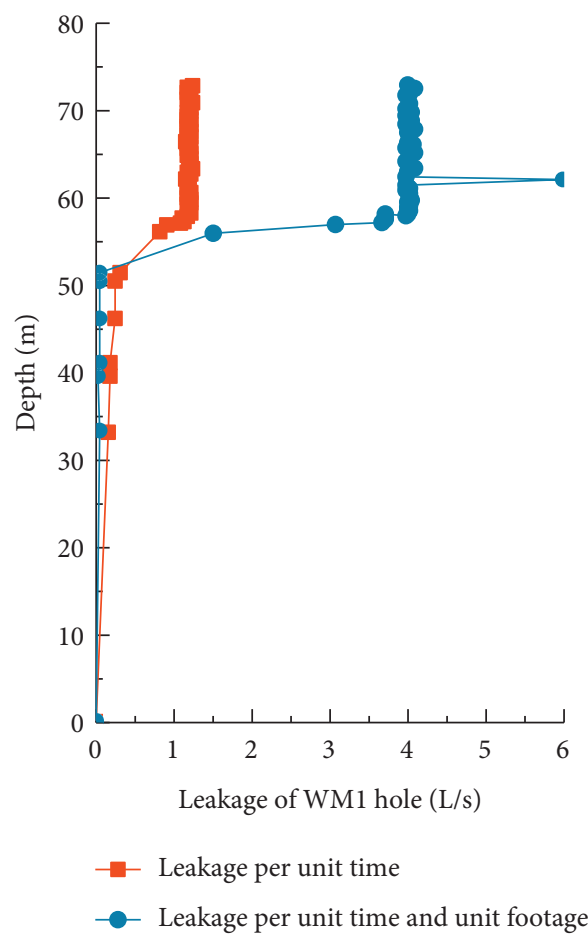

(a)

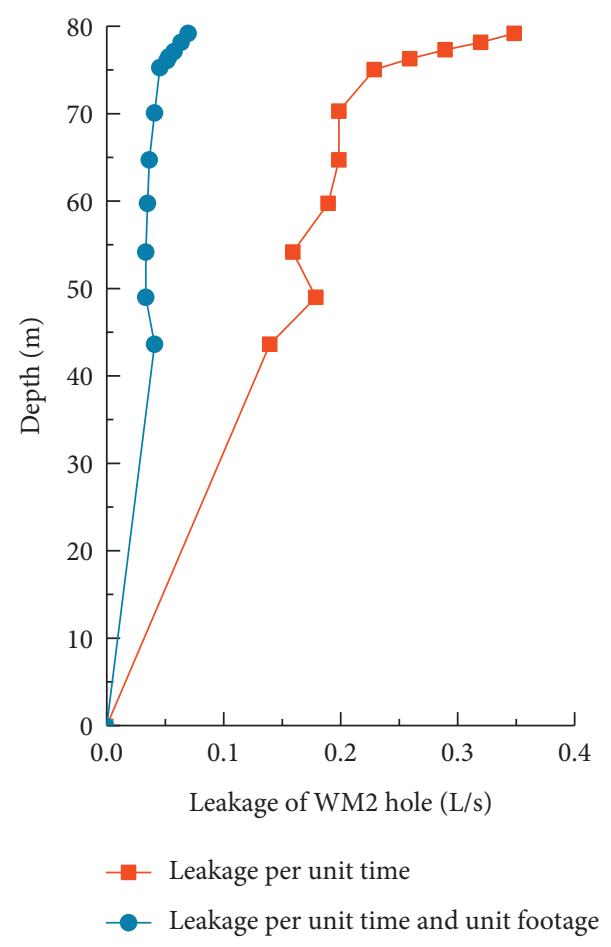

(b)

Figure 18: Change curve of drilling fluid leakage.

\section{Conclusions}

(1) Along the strike direction, the subsidence of strata in caving zone (within about $20 \mathrm{~m}$ above coal seam roof) has no characteristics of skewness. However, the subsidence of strata in fissure zone and bending subsidence zone shows the characteristics of skewness, which indicate that the subsidence of strata on the side of open-off cut is relatively large. The skewed subsidence of fractured strata in bedrock is the reason of skewed subsidence of surface. The research results can provide reference for finding the maximum subsidence point

(2) An interface exists in overburden $40 \mathrm{~m}-50 \mathrm{~m}$ above the coal seam roof. The horizontal movement of overburden from the interface to the surface generally moves from both sides to the middle, while the horizontal movement of overburden from coal seam roof to the interface generally moves from the middle to both sides. The zero point of horizontal movement of strata in the strike direction is not in the middle of mining area, but inclined to the side of open-off cut. The zero point of horizontal movement of strata above and below the interface is not coincident, so there are horizontal movement areas in different directions and in the same direction

(3) The damage of overburden is zonal. There are no cracks through the whole layer in aeolian sand, while there are cracks through the whole layer in bedrock, mainly distributing on both sides of the mining area.
There are local cracks through the bedrock in caving zone of central mining area and the lower part of fracture zone. This study is of great significance to the protection of water resources

(4) The heights of water flowing fractured zone are $62.5 \mathrm{~m}$ and $62.8 \mathrm{~m}$, respectively, in numerical simulation and physical similar simulation study, both of which are in the range of $35.74 \mathrm{~m}-62.89 \mathrm{~m}$ measured in the field. To some extent, the results of numerical simulation and similar simulation can provide some reference for water-preserved mining.

\section{Data Availability}

The research data used to support the findings of this study are available from the corresponding author upon request.

\section{Conflicts of Interest}

The authors declare there are no conflicts of interest regarding the publication of this paper.

\section{Acknowledgments}

This work was supported by the National Key R\&D Program of China (2016YFC0501100) and the Program of State Key Laboratory of Water Resource Protection and Utilization in Coal Mining (GJNY-18-77). The authors gratefully acknowledge the financial support of the abovementioned agencies. 


\section{References}

[1] H. Zhu, F. L. He, and Y. Q. Fan, "Development mechanism of mining-induced ground fissure for shallow burial coal seam in the mountains area of southwestern China: a case study," Acta Geodynamica et Geomaterialia, vol. 15, no. 4, pp. 349-362, 2018.

[2] L. Jiang, P. Kong, P. Zhang et al., "Dynamic analysis of the rock burst potential of a longwall panel intersecting with a fault," Rock Mechanics and Rock Engineering, vol. 53, no. 4, pp. 1737-1754, 2020.

[3] F. Wang, N. Liang, and G. Li, "Damage and failure evolution mechanism for coal pillar dams affected by water immersion in underground reservoirs," Geofluids, vol. 2019, Article ID 2985691, 12 pages, 2019.

[4] S. Wang, X. Li, and D. Wang, "Mining-induced void distribution and application in the hydro-thermal investigation and control of an underground coal fire: a case study," Process Safety and Environmental Protection, vol. 102, pp. 734-756, 2016.

[5] S. Wang, X. Li, and S. Wang, "Separation and fracturing in overlying strata disturbed by longwall mining in a mineral deposit seam," Engineering Geology, vol. 226, pp. 257-266, 2017.

[6] V. Palchik, "Bulking factors and extents of caved zones in weathered overburden of shallow abandoned underground workings," International Journal of Rock Mechanics and Mining Sciences, vol. 79, pp. 227-240, 2015.

[7] V. Palchik, "Experimental investigation of apertures of mining-induced horizontal fractures," International Journal of Rock Mechanics and Mining Sciences, vol. 47, no. 3, pp. 502-508, 2010.

[8] A. Guney and M. Gul, "Analysis of surface subsidence due to longwall mining under weak geological conditions: Turgut basin of Yatağan-Muğla (Turkey) case study," International Journal of Mining, Reclamation and Environment, vol. 33, no. 7, pp. 445-461, 2019.

[9] X. Yang, G. Wen, L. Dai, H. Sun, and X. Li, "Ground subsidence and surface cracks evolution from shallow-buried close-distance multi-seam mining: a case study in Bulianta coal mine," Rock Mechanics and Rock Engineering, vol. 52, no. 8, pp. 2835-2852, 2019.

[10] H. W. Ma, W. H. Sui, and J. M. Ni, "Environmentally sustainable mining: a case study on surface subsidence control of grouting into overburden," Environmental Earth Sciences, vol. 78, no. 320, pp. 1-15, 2019.

[11] B. Elberling, J. Søndergaard, L. A. Jensen et al., "Arctic vegetation damage by winter-generated coal mining pollution released upon thawing," Environmental Science \& Technology, vol. 41, no. 7, pp. 2407-2413, 2007.

[12] Q. H. Wu, K. Liu, C. Q. Song et al., "Remote sensing detection of vegetation and landform damages by coal mining on the Tibetan Plateau," Sustainability, vol. 10, no. 3851, pp. 1-17, 2018.

[13] S. N. Zhou, Theory of Gas Occurrence and Flow in Coal Seam, China Coal Industry Publishing House, Beijing, China, 1999.

[14] T. Q. Liu, "Influence of mining activities on mine rock mass and control engineering," Journal of China Coal Society, vol. 20, no. 1, pp. 1-5, 1995.

[15] M. Bai, D. Elsworth, and T. Q. Liu, "Numerical analysis of rock deformation and flow of underground water caused by coal extraction-stable flow," Journal of China Coal Society, vol. 23, no. 6, pp. 289-294, 1998.
[16] Q. X. Huang and X. G. Xia, "Division of four zones in mining strata and surface movement," Journal of Mining \& Safety Engineering, vol. 33, no. 3, pp. 393-397, 2016.

[17] Y. G. Wang, W. B. Guo, E. H. Bai et al., "Characteristics and mechanism of overlying strata movement due to high-intensity mining," Journal of China Coal Society, vol. 43, no. S1, pp. 28-35, 2018.

[18] X. B. Li, W. R. He, and Z. H. Xu, "Study on law of overlying strata breakage and migration in downward mining of extremely close coal seams by physical similarity simulation," Advances in Civil Engineering, vol. 2020, Article ID 2898971, 11 pages, 2020.

[19] K. Zhang, T. H. Yang, H. B. Bai et al., "Longwall mininginduced damage and fractures: field measurements and simulation using FDM and DEM coupled method," International Journal of Geomechanics, vol. 18, no. 1, Article ID 04017127, 2018.

[20] L. Li, K. Wu, Z. Q. Hu et al., "Analysis of developmental features and causes of ground cracks induced by oversized working face mining in an Aeolian sand area," Environmental Earth Sciences, vol. 76, no. 135, pp. 1-12, 2017.

[21] G. Q. He, L. Yang, and G. D. Ling, Mining Subsidence, China University of Mining and Technology Press, Xuzhou, China, 1991.

[22] Q. S. Li and J. T. Guo, "Surface damage characteristics in shallow-buried coal seam with strong disturbance mining: taking Shendong coal mine district as an example," China Mining Magazine, vol. 27, no. 4, pp. 106-112, 2018.

[23] E. Hoek and E. T. Brown, Underground Excavation in Rock, Institute of Mining and Metallurgy, London, UK, 1980.

[24] E. Hoek, C. Carranza-Torres, and B. Corkum, "Hoek-Brown failure criterion-2002 edition," in Proceedings of NARMSTAC 2002, Toronto, Canada, 2002.

[25] Y. H. Su, L. Z. Feng, Z. Y. Li et al., "Quantification of elements for geological strength index in Hoek-Brown criterion," Chinese Journal of Rock Mechanics and Engineering, vol. 28, no. 4, pp. 679-686, 2009.

[26] J. S. Sun and W. B. Lu, "Modification of Hoek-Brown criterion and its application," Engineering Journal of Wuhan University, vol. 41, no. 1, pp. 63-66, 2008.

[27] E. Hoek and E. T. Brown, "Practical estimates of rock mass strength," International Journal of Rock Mechanics and Mining Sciences, vol. 34, no. 8, pp. 1165-1186, 1997.

[28] P. Marinos and E. Hoek, "Estimating the geotechnical properties of heterogeneous rock masses such as flysch," Bulletin of Engineering Geology and the Environment, vol. 60, no. 2, pp. 85-92, 2001.

[29] G. C. Zhang and F. L. He, "Asymmetric failure and control measures of large cross-section entry roof with strong mining disturbance and fully-mechanized caving mining," Chinese Journal of Rock Mechanics and Engineering, vol. 35, no. 4, pp. 806-818, 2016.

[30] J. M. Xu, Movement Law of the Overlying Strata above Large Mining Height Longwall Face-End with Shallow Cover and Its Effect on Ground Deformation, China University of Mining and Technology, Xuzhou, China, 2017. 